\title{
Analisa Kerusakan dan Pengaruh Variasi Massa Refrigerant Terhadap Koefisien Prestasi (COP) Sistem Pengkondisian Udara AC Praktikum lab mesin
}

\author{
Sobar Arief \\ Teknik Mesin, Fakultas Teknik \\ Universitas Maarif Hasyim Latif, Sidoarjo, Indonesia \\ e-mail : sobar-arief@student.umaha.ac.id
}

\begin{abstract}
ABSTRAK
Udara dipengaruhi oleh keadaan disekitar ruangan apabila dalam ruangan tersebut banyak orang maka udara disekitar lama-kelamaan akan terasa panas. Untuk menghindari udara ruangan yang panas maka dipergunakanlah alat atau sistem pendingin udara atau yang biasa kita sebut air conditioning (AC). Terdapat Mesin alat peraga AC Split di Lab Mesin dalam keadaan rusak, disayangkan jika tidak bisa digunakan,sehingga perlu dilakukan langkah trouble shooting dengan cek kondisi AC. Data kinerja yang di dapat dari penelitian saat diisi refrigerant dengan variasi massa 400 gram mampu menghasilkan laju aliran massa $(m)$ adalah $0.082 \mathrm{kj} / \mathrm{s}$ kapasitas pendinginan pada Kondensor sebesar $0.082 \mathrm{~kg} / \mathrm{s}$, kapasitas pendingin pada Evaporator $\left(Q_{\text {in }}\right)$ sebesar $13.94 \mathrm{kj} / \mathrm{s}$ dan koefisien prestasi sebesar 0.94 . Tujuan dari penelitian ini adalah Mengetahui gejala kerusakan dengan mengidentifikasi alat peraga ac tersebut, mengetahui pengaruh variasi massa refrigerant terhadap Kapasitas Pendinginan $(Q$ in), dan juga mengetahui koefisien prestasi (COP) sistem pendinginan udara sistem AC Midea 1PK. Refigerant merupakan komponen penting dalam sistem pending udara, jika tidak ada refrigerant maka sistem tidak akan bekerja. Begitu pula jika kapasitasnya kurang, maka sistem tidak bekerja maksimal dan proses pendinginannya juga kurang maksimal.
\end{abstract}

Kata kunci: AC split, COP , Koefisien Prestasi, Refrigerant, Trouble shooting.

BAB 1

PENDAHULUAN

\subsection{Latar Belakang}

Udara adalah bagian terpenting dalam kehidupan dibumi ini, tanpa adanya udara mahluk hidup tidak bisa bernafas yang akhirnya akan menyebabkan kematian. Udara dipengaruhi oleh keadaan disekitar ruangan apabila dalam ruangan tersebut banyak orang maka udara disekitar lamakelamaan akan terasa panas hal ini akan menyebabkan manusia kurang nyaman berada pada ruangan yang panas tersebut. Namun kondisi tersebut akan bertambah jika manusia berada dalam ruangan yang tertutup, panas tersebut akan bertambah berkali-kali lipat karena tidak adanya sirkulasi udara, misalkan pada ruangan. Untuk menghindari temperatur udara ruangan yang panas maka dipergunakanlah alat atau sistem pendingin udara atau yang biasa kita sebut air conditioning (AC). Sistem pendingin udara merupakan suatu rangkaian alat yang dapat menghasilkan dan mengalirkan udara dengan temperature yang rendah sesuai dengan kebutuhan sang pemakai. Dalam lab teknik mesin terdapat alat peraga AC Split yang tidak berfungsi sama sekali. Sangat disayangkan jika tidak bisa digunakan, karena bisa membantu metode pembelajaran perkuliahan di teknik Mesin Universitas Maarif Hasyim Latief. Dan juga menambah alat praktikum yang masih sedikit. Kondisi AC yang hanya bisa mode kipas dari indoor dan outdoor unit tidak bekerja. Dan juga banyak pipa rusak akibat bengkok yang menimbulkan terjadi kebocoran refrigerant.

\section{METODE PENELITIAN}

\subsection{Rumusan Masalah}

Perumusan masalah dalam penelitian ini adalah sebagai berikut:

a) Apa yang menyebabkan Alat peraga $\mathrm{AC}$ Split tidak berfungsi

b) Bagaimana pengaruh variasi massa refrigerant terhadap Kapasitas Pendinginan $(Q$ in)

c) Berapa koefisien prestasi (COP) sistem AC Midea 1PK 


\subsection{Batasan Masalah}

Dalam penelitian ini masalah dibatasi sebagai berikut:

1. Pengujian dilakukan langsung pada Ac merk Midea $1 \mathrm{pk}$

2. Beban pendinginan adalah konstan

3. Refrigerant yang digunakan adalah $\mathrm{R} 22$

\subsection{Tujuan}

Tujuan dari penelitian ini adalah sebagai berikut:

1. Mengetahui gejala kerusakan dengan mengidentifikasi alat peraga ac tersebut

2. Mengetahui pengaruh variasi massa refrigerant terhadap Kapasitas Pendinginan $(Q$ in $)$

3. Mengetahui koefisien prestasi (COP) sistem pendinginan udara sistem AC Midea 1PK

\section{BAB II \\ KAJIAN TEORI}

\subsection{Persamaan Energi Aliran Mantap}

Di dalam kebanyakan sistem refrigerasi dan pengkondisian udara, laju aliran massa tidak berubah dari waktu ke waktu (kalaupun ada, hanya perubahan keci), karena itu laju alirandapat dianggap mantap.

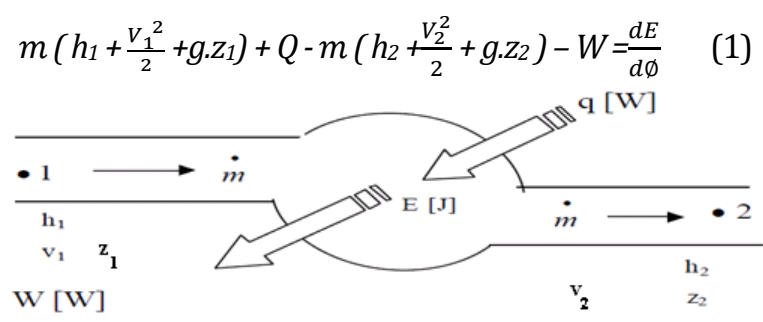

Gambar 2.1 Kesetimbangan energi pada sebuah volume atur yang mengalami laju aliran mantap

Dimana:

$\dot{m}=$ Laju aliran massa refrigerant $(\mathrm{kg} / \mathrm{s})$

$h=$ Entalpi $(\mathrm{J} / \mathrm{kg})$

$V=\operatorname{Kecepatan}(\mathrm{m} / \mathrm{s})$

$z=$ Ketinggian $(\mathrm{m})$

$g=$ Percepatan gravitasi $\left(9,81 \mathrm{~m} / \mathrm{s}^{2}\right)$

$Q=$ Laju aliran energy dalam bentuk kalor (W)

$W=$ Laju aliran energy dalam bentuk kerja (W)

$E=$ Energi dalam system (J)

Karena perhatian hanya dibatasi pada masalah proses aliran mantap, maka tidak ada perubahan harga Eterhadap waktu, karena itu $d E / d \theta=0$, dan persamaan energi aliran mantap menjadi:

$m\left(h_{1}+\frac{V_{1}{ }^{2}}{2}+g \cdot z_{1}\right)+q=m\left(h_{2}+\frac{V_{2}^{2}}{2}+g \cdot z_{2}\right)+W(2)$

\subsection{Proses Kompresi}

Proses kompresi dianggap berlangsung secara adiabatik artinya tidak ada panas yang dipindahkan baik masuk ataupun keluar sistem.

$$
W c=m\left(h_{2}-h_{1}\right)
$$

Dimana : $W c=$ Daya kompresor $(\mathrm{kW})$

$m=$ Laju aliran massa refrigerant $(\mathrm{kg} / \mathrm{s})$

$h_{1}=$ Entalpi refrigerant pada titik $1(\mathrm{~kJ} / \mathrm{kg})$

$h_{2}=$ Entalpi refrigerant pada titik $2(\mathrm{~kJ} / \mathrm{kg})$

\subsection{Proses Evaporasi dan Kondensasi}

Pada proses evaporasi dan kondensasi perubahan energi kinetik dan energi potensial diabaikan sehingga harga $v_{2}{ }^{2}$ dan g.z pada titik 1 dan titik 2 dianggap 0 .

$$
\begin{aligned}
& Q \text { in }=m\left(\mathrm{~h}_{1}-\mathrm{h}_{4}\right) \\
& \text { Dimana: } Q \text { in }=\text { Kapasitas pendinginan }(\mathrm{kW}) \\
& m=\text { Laju aliran massa refrigerant }(\mathrm{kg} / \mathrm{s}) \\
& \mathrm{h}_{1}=\text { Entalpi refrigerant pada titik } 1(\mathrm{~kJ} / \mathrm{kg}) \\
& \mathrm{h}_{4}=\text { Entalpi refrigerant pada titik } 4(\mathrm{~kJ} / \mathrm{kg})
\end{aligned}
$$

laju aliran kalor pada proses kondensasi (kapasitas pengembunan) dirumuskan sebagai berikut :

$Q$ out $=m\left(\mathrm{~h}_{2}-\mathrm{h}_{3}\right)$

Dimana: $Q_{\text {out }}=$ Kapasitas pengembunan $(\mathrm{kW})$

$m=$ Laju aliran massa refrigerant $(\mathrm{kg} / \mathrm{s})$

$\mathrm{h}_{2}=$ Entalpi refrigerant pada titik $2(\mathrm{~kJ} / \mathrm{kg})$

$\mathrm{h}_{3}=$ Entalpi refrigerant pada titik $3(\mathrm{~kJ} / \mathrm{kg})$

\subsection{Throttling Proses}

Proses ini terjadi pada pipa kapiler atau pada katub ekspansi. Pada proses ini tidak ada kerja yang dilakukan atau ditimbulkan sehingga $\mathrm{W}=0$.

$$
h_{3}=h_{4}
$$

\subsection{Koefisien Prestasi (COP)}

Koefisien prestasi dari sistem refrigerasi adalah perbandingan besarnya panas dari ruang pendingin (efek refrigerasi) dengan besarnya kerja yang dilakukan kompresor.

$C O P=\frac{h 1-h 4}{h 2-h 1}$ 


\section{BAB III \\ METODOLOGI PENELITIAN}

\subsection{Diagram alur}

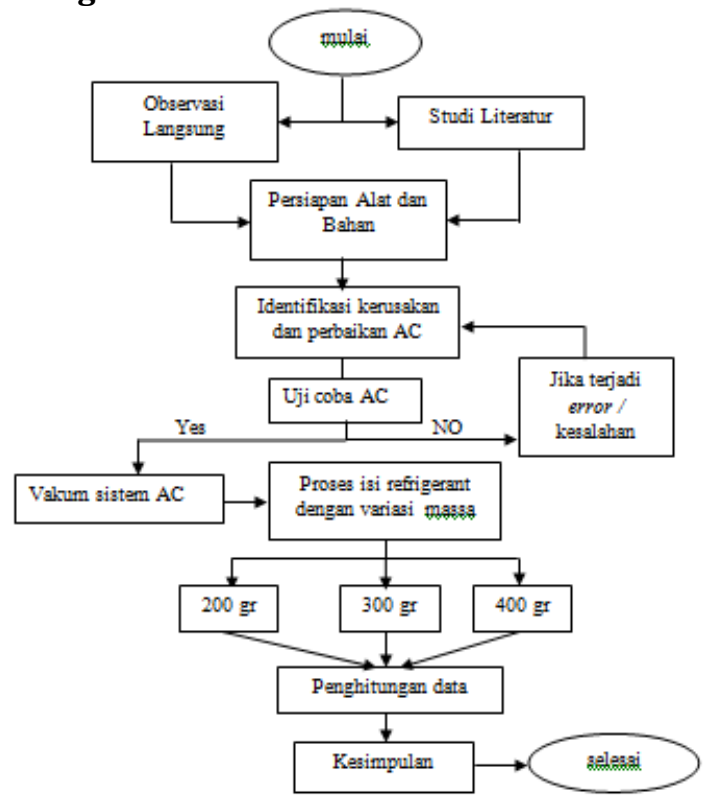

\subsection{Bahan dan Alat}

Maka dari itu yang pertama kali disiapkan untuk analisa refrigerant maka kita siapkan yaitu :

Bahan :

1 Refrigeran 22

2 Kapasitor kompresor $35 \mathrm{uF}$

3 Kapasitor fan 1,5uf

4 Sealtip

Alat:

1 unit AC split

2 Manifold Gauge

3 Kunci Inggris

4 Kunci L

5 Tespen

6 Alat vakum refrigerant

7 Swagging tool

\subsection{Tempat Dan Waktu}

Tempat melakukan analisa tersebut dilakukan di lab Teknik MESIN Universitas Maarif Hasyim Latief Waktu analisa penelitian dilakukan dalam tabel berikut : Tabel 3.1 Waktu penelitian

\begin{tabular}{|l|l|l|}
\hline no & \multicolumn{1}{|c|}{ Hari } & \multicolumn{1}{|c|}{ Kegiatan } \\
\hline 1 & $\begin{array}{l}\text { Sabtu 18 Mei } \\
2019\end{array}$ & $\begin{array}{l}\text { Cek kondisi AC di lab } \\
\text { Mesin }\end{array}$ \\
\hline 2 & $\begin{array}{l}\text { Sabtu 15 juni } \\
2019\end{array}$ & $\begin{array}{l}\text { Perbaiki kerusakan } \\
\text { pada AC }\end{array}$ \\
\hline 3 & $\begin{array}{l}\text { Sabtu 22 Juni } \\
2019\end{array}$ & $\begin{array}{l}\text { Uji coba variasi massa } \\
\text { 200 gram }\end{array}$ \\
\hline 4 & $\begin{array}{l}\text { Sabtu 29 juni } \\
2019\end{array}$ & $\begin{array}{l}\text { Uji coba variasi massa } \\
\text { 300 gram }\end{array}$ \\
\hline 5 & $\begin{array}{l}\text { Sabtu 6 Juli } \\
2019\end{array}$ & $\begin{array}{l}\text { Uji coba variasi massa } \\
\text { 400 gram }\end{array}$ \\
\hline
\end{tabular}

\subsection{Proses Penelitian}

a) Langkah persiapan

Pemeriksaan seluruh peralatan uji dan perlengkapannya merupakan langkah pertama yang harus dilakukan untuk menunjang proses penelitian agar bisa berjalan dengan baik dan lancar. Hal-hal yang harus diperhatikan sebelum penelitian adalah:

1) Memastikan unit AC lengkap dengan terdiri kompresor, kondensor, pipa kapiler dan evaporator

2) Memeriksa sirip-sirip pada evaporator dan kondensor tidak rusak dan buntu

3) Memastikan kipas kondensor dan blower evaporator bekerja dengan baik

b) Langkah Penelitian

1) Mengidentifikasi kerusakan pada unit AC tersebut

2) Test running untuk trial ac tersebut ketika sudah memperbaiki kerusakan tersebut

3) Pasang manifold gauge dan Alat vakum pada katup service pipa suction AC untuk memvakum udara atau refrigerant yang ada pada AC tersebut selama kurang lebih 10 sampai 15 menit

4) Vakum diganti dengan tabung refrigerant dan memulai isi refrigerant sesuai massa yang akan diuji

5) Massa refrigerant juga ditimbang menggunakan timbangan untuk mengetahui massa yang akan diuji

6) Test running AC selama 30 menit dan amati perkembangan ac selama tes running

7) Jika tidak mengalami error, maka dilakukan uji massa berikutnya dengan terlebih dahulu proses vakum unit $\mathrm{AC}$

c) Pengambilan Data

1) Mempersiapkan alat tulis dan lembar pengambilan data

2) Mempersipkan dan meletakkan alat ukur pada posisinya dan memastikan bekerja dengan baik

3) Mengukur parameter-parameter tekanan dan temperature refrigerant yang masuk dan keluar dari kompresor, kondensor, katup ekspansi dan evaporator

4) Mencatat semua data dari hasil pengamatan 
5) Mematikan mesin

6) Mengulangi langkah penelitian 1-7 untuk setiap kenaikan massa refrigerant

7) Mematikan mesin dan merapikan peralatan dan alat ukur yang telah digunakan

\subsection{Bagian yang akan diamati}

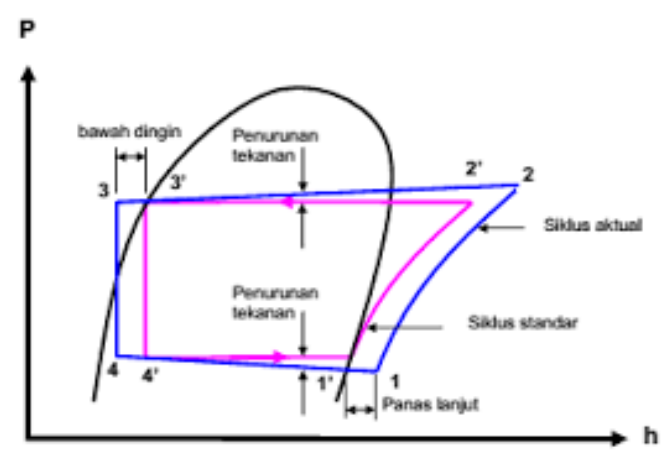

Gambar 3.2 Siklus Kompresi Uap Aktual

Dikarenakan keterbatasan tempat untuk melakukan pengukuran pada titik 4 dan juga jarak yang sangat pendek antara Expansion Valve dan Evaporator maka dianggap tidak terjadi penurunan tekanan akibat panjang pipa.

\section{BAB IV \\ PERHITUNGAN DAN ANALISIS DATA}

\subsection{Identifikasi Kerusakan dan Perbaikannya}

Tabel 4.1 tabel kerusakan dan perbaikan AC praktikum Lab Mesin

\begin{tabular}{|c|l|l|}
\hline No & \multicolumn{1}{|c|}{ Kerusakan } & \multicolumn{1}{|c|}{ Perbaikan } \\
\hline 1 & $\begin{array}{l}\text { Kompresor } \\
\text { tidak bekerja }\end{array}$ & $\begin{array}{l}\text { Cek kelistrikan dan } \\
\text { ganti kapasitor } \\
\text { Running untuk 1 pk } \\
\text { dengan ukuran 30 } \mu \mathrm{F}\end{array}$ \\
\hline 2 & AC tidak dingin & $\begin{array}{l}\text { Isi Freon (dicek lewat } \\
\text { manifold, Freon dalam } \\
\text { keadaan habis) }\end{array}$ \\
\hline 3 & $\begin{array}{l}\text { Dingin hanya } \\
\text { sebentar }\end{array}$ & $\begin{array}{l}\text { Tes kebocoran Freon, } \\
\text { sambungan pada } \\
\text { katup service bocor }\end{array}$ \\
\hline 4 & $\begin{array}{l}\text { Fan outdoor } \\
\text { lemah }\end{array}$ & $\begin{array}{l}\text { Ganti kapasitor fan } \\
\text { sebesar 1.5 } \mu \mathrm{F}\end{array}$ \\
\hline 5 & $\begin{array}{l}\text { Hembusan } \\
\text { angin indoor } \\
\text { lemah }\end{array}$ & $\begin{array}{l}\text { Bersihkan filter dalam } \\
\text { unit indoor }\end{array}$ \\
\hline
\end{tabular}

\subsection{Perhitungan Unjuk Kerja Sistem Dengan Massa Refrigeran 200 Gram}

Data data hasil Percobaan dapat dilihat pada tabel dan gambar di bawah ini

Tabel 4.2 Data analisa perhitungan massa Refrigeran R22 200 gram

\begin{tabular}{|c|c|c|c|c|c|c|}
\hline Masa & $\begin{array}{c}\mathrm{P}_{\mathrm{t}} \\
(\mathrm{Bar})\end{array}$ & $\begin{array}{c}\mathrm{T}_{\mathrm{t}} \\
(\cdot \mathrm{C})\end{array}$ & $\begin{array}{c}\mathrm{P}_{2} \\
(\mathrm{Bar})\end{array}$ & $\begin{array}{c}\mathrm{T}_{2} \\
(\cdot \mathrm{C})\end{array}$ & $\begin{array}{c}\mathrm{P}_{3} \\
(\mathrm{Bar})\end{array}$ & $\begin{array}{c}\mathrm{T}_{3} \\
(\cdot \mathrm{C})\end{array}$ \\
\hline $\begin{array}{c}200 \\
\text { gram }\end{array}$ & 1,7 & 27 & 12.13 & 58.5 & 11.4 & 27.2 \\
\hline
\end{tabular}

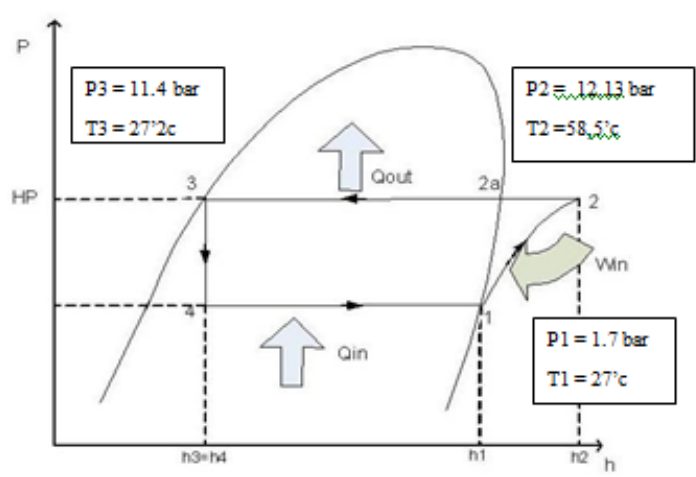

Gambar 4.1 Diagram P-h Siklus Kompresi Uap Aktual Dengan Massa Refrigerant 200 Gram.

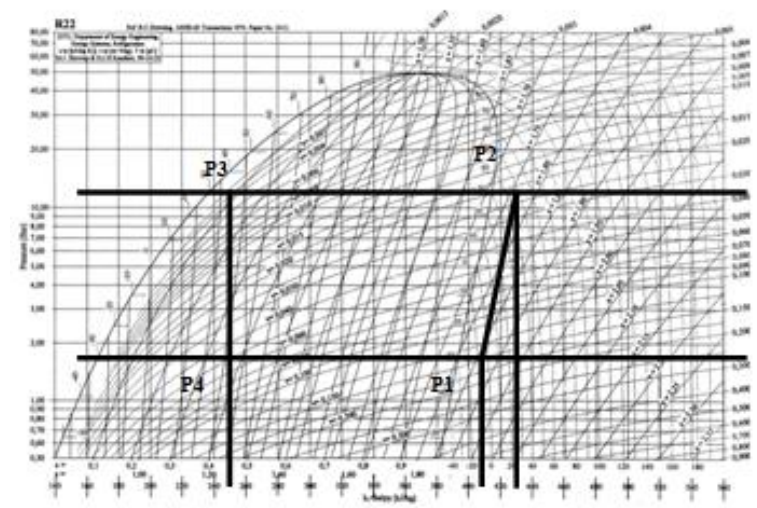

Gambar 4.2 P-h diagram variasi massa 200 gram

a) Keadaan titik 1

$\mathrm{P}_{1}=1.7$ bar

$\mathrm{T}_{1}=27^{\prime} \mathrm{C}$

Maka $\mathrm{h}_{1}$ diperoleh dari grafik adalah $395 \mathrm{kj} / \mathrm{kg}$

b) Keadaan titik 2

$\mathrm{P}_{2}=12,13$ bar

$\mathrm{T}_{2}=58,5^{\circ} \mathrm{C}$

Maka $\mathrm{h}_{2}$ diperoleh dari grafik adalah $417 \mathrm{kj} / \mathrm{kg}$

c) Keadaan titik 3

$\mathrm{P}_{3}=11,4$ bar $=1140 \mathrm{kpa}$

$\mathrm{T}_{3}=27,2^{\circ} \mathrm{C}$

Dari grafik pada lampiran maka diperoleh $\mathrm{h}_{3}=$ $238 \mathrm{~kJ} / \mathrm{kg}$

d) Keadaan titik 4

Keadaan ini terjadi pada pipa kapiler yang tidak versible maka $\mathrm{h}_{4}=\mathrm{h}_{3}=238 \mathrm{~kJ} / \mathrm{kg}$ 
e) Efek refrigerasi :

$\mathrm{h}_{1}-\mathrm{h}_{4}=395 \mathrm{kj} / \mathrm{kg}-238 \mathrm{kj} / \mathrm{kg}=157 \mathrm{kj} / \mathrm{kg}$

f) Laju Aliran Massa Refrigerant : Kapasitas refrijerasi dibagi efek refrijerasi

$\mathrm{Wc}=\dot{m}\left(\mathrm{~h}_{2}-\mathrm{h}_{1}\right)$

$$
\begin{aligned}
& \dot{m}=\frac{W c}{h_{2}-h_{1}}=\frac{746 \mathrm{watt}}{417 \frac{\mathrm{kj}}{\mathrm{kg}}-395 \frac{\mathrm{kj}}{\mathrm{kg}}}=\frac{0.746 \frac{\mathrm{kj}}{\mathrm{s}}}{417 \frac{\mathrm{kj}}{\mathrm{kg}}-395 \frac{\mathrm{kj}}{\mathrm{kg}}} \\
& =\frac{0.746 \frac{\mathrm{kj}}{\mathrm{s}}}{(417-395) \frac{\mathrm{kj}}{\mathrm{kg}}}=0.034 \frac{\mathrm{kg}}{\mathrm{s}}
\end{aligned}
$$

g) $\mathrm{Qc}=\dot{m}\left(\mathrm{~h}_{2}-\mathrm{h}_{3}\right)$

$$
\begin{aligned}
& =0.034 \frac{\mathrm{kg}}{\mathrm{s}}(417 \mathrm{kj} / \mathrm{kg}-238 \mathrm{kj} / \mathrm{kg}) \\
& =0.034 \frac{\mathrm{kg}}{\mathrm{s}}\left(179 \frac{\mathrm{kj}}{\mathrm{kg}}\right)=6.086 \frac{\mathrm{kj}}{\mathrm{s}}
\end{aligned}
$$

h) $\mathrm{Qe}=\dot{m}\left(\mathrm{~h}_{1}-\mathrm{h}_{4}\right)$

$$
\begin{aligned}
& =0.034 \frac{\mathrm{kg}}{\mathrm{s}}(395 \mathrm{kj} / \mathrm{kg}-238 \mathrm{kj} / \mathrm{kg}) \\
& =0.034 \frac{\mathrm{kg}}{\mathrm{s}}\left(157 \frac{\mathrm{kj}}{\mathrm{kg}}\right)=5.338 \frac{\mathrm{kj}}{\mathrm{s}}
\end{aligned}
$$

i) $\quad \mathrm{COP}=\frac{h 1-h 4}{h 2-h 1}=\frac{395 \frac{\mathrm{kj}}{\mathrm{kg}}-238 \frac{\mathrm{kg}}{\mathrm{kj}}}{417 \frac{\mathrm{kj}}{\mathrm{kg}}-238 \frac{\mathrm{kj}}{\mathrm{kg}}}=\frac{157}{179}=0.877$

j) Tabel 4.4 Data Perhitungan Yang Akan Dipakai Buat Analisa

\begin{tabular}{|c|c|c|c|c|}
\hline Massa & $\dot{m}$ & Qc & Qe & COP \\
\hline $\begin{array}{c}200 \\
\text { gram }\end{array}$ & $\begin{array}{c}0.034 \\
\frac{\mathrm{kg}}{\mathrm{s}}\end{array}$ & $\begin{array}{c}6.086 \\
\frac{\mathrm{kj}}{\mathrm{s}}\end{array}$ & $\begin{array}{c}5.338 \\
\frac{\mathrm{kj}}{\mathrm{s}}\end{array}$ & 0.877 \\
\hline
\end{tabular}

\subsection{Perhitungan Unjuk Kerja Sistem Dengan Massa Refrigeran 300 Gram}

Tabel 4.5 Data analisa perhitungan massa Refrigeran R22 300 gram

\begin{tabular}{|c|c|c|c|c|c|c|}
\hline Massa & $\begin{array}{c}\text { P1 } \\
(\text { (Bar) }\end{array}$ & $\begin{array}{c}\text { T1 } \\
(\cdot \mathrm{C})\end{array}$ & $\begin{array}{c}\text { P2 } \\
(\text { Bar })\end{array}$ & $\begin{array}{c}\text { T2 } \\
(\cdot \mathrm{C})\end{array}$ & $\begin{array}{c}\text { P3 } \\
(\text { Bar })\end{array}$ & $\begin{array}{c}\text { T3 } \\
(\cdot \mathrm{C})\end{array}$ \\
\hline $\begin{array}{c}300 \\
\text { gram }\end{array}$ & 5,5 & 26,5 & 15,17 & 51,8 & 15,03 & 28,2 \\
\hline
\end{tabular}

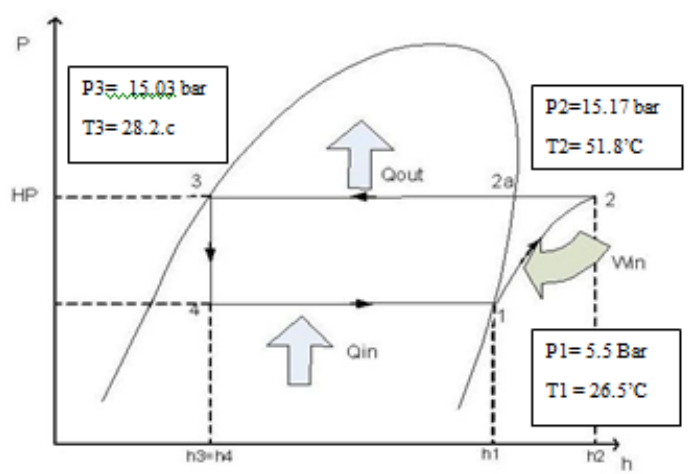

Gambar 4.3 Diagram P-h Siklus Kompresi Uap Aktual Dengan Massa Refrigerant 300 Gram.

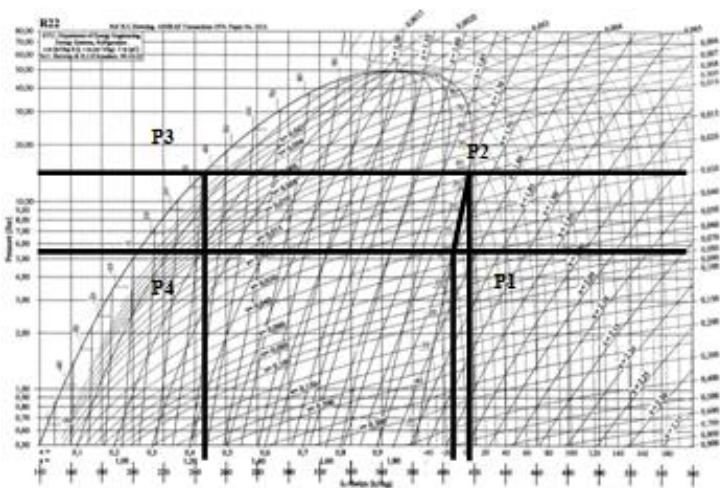

Gambar 4.4 P-h diagram variasi massa 300 gram

a) Keadaan titik 1

$\mathrm{P}_{1}=5,5$ bar

$\mathrm{T}_{1}=26,5^{\prime} \mathrm{c}$

$\mathrm{h}_{1}$ diketahui melalui diagram $\mathrm{p}-\mathrm{h}$ yaitu $\mathrm{h}_{1}=$ $405 \mathrm{kj} / \mathrm{kg}$

b) Keadaan titik 2

$\mathrm{P}_{2}=15,17$ bar

$\mathrm{T}_{2}=51,8^{\circ} \mathrm{C}$

$\mathrm{H}_{2}$ diketahui melalui diagram $p-h$ yaitu $\mathrm{h}_{2}=$ $418 \mathrm{kj} / \mathrm{kg}$

c) Keadaan titik 3

$\mathrm{P}_{3}=15,03 \mathrm{bar}$

$\mathrm{T}_{3}=28,2^{\circ} \mathrm{C}$

Dari grafik pada lampiran maka diperoleh $\mathrm{h}_{3}=245 \mathrm{~kJ} / \mathrm{kg}$

d) Keadaan titik 4

Keadaan ini terjadi pada pipa kapiler yang tidak versible maka

$\mathrm{h}_{4}=\mathrm{h}_{3}=245 \mathrm{~kJ} / \mathrm{kg}$

e) Efek refrigerasi :

$\mathrm{h}_{1}-\mathrm{h}_{4}=405 \mathrm{kj} / \mathrm{kg}-245 \mathrm{kj} / \mathrm{kg}=160 \mathrm{kj} / \mathrm{kg}$

f) Laju Aliran Massa Refrigerant : Kapasitas refrijerasi dibagi efek refrigerasi

$\mathrm{Wc}=\dot{m}\left(\mathrm{~h}_{2}-\mathrm{h}_{1}\right) \leftrightarrow$

$$
\begin{aligned}
& \dot{m}=\frac{W c}{h_{2}-h_{1}}=\frac{746 \mathrm{watt}}{418 \frac{\mathrm{kj}}{\mathrm{kg}}-405 \frac{\mathrm{kj}}{\mathrm{kg}}}=\frac{0.746 \frac{\mathrm{kj}}{\mathrm{s}}}{418 \frac{\mathrm{kj}}{\mathrm{kg}}-405 \frac{\mathrm{kj}}{\mathrm{kg}}} \\
& m=\frac{0.746 \frac{\mathrm{kj}}{\mathrm{s}}}{(418-405) \frac{\mathrm{kj}}{\mathrm{kg}}}=0.057 \frac{\mathrm{kg}}{\mathrm{s}}
\end{aligned}
$$

g) $\mathrm{Qc}=\dot{m}\left(\mathrm{~h}_{2}-\mathrm{h}_{3}\right)$

$$
\begin{aligned}
& =0.057 \frac{\mathrm{kg}}{\mathrm{s}}(418 \mathrm{kj} / \mathrm{kg}-245 \mathrm{kj} / \mathrm{kg}) \\
& =0.057 \frac{\mathrm{kg}}{\mathrm{s}}\left(173 \frac{\mathrm{kj}}{\mathrm{kg}}\right)=9,861 \frac{\mathrm{kj}}{\mathrm{s}}
\end{aligned}
$$

h) $\mathrm{Qe}=\dot{m}\left(\mathrm{~h}_{1}-\mathrm{h}_{4}\right)$

$$
\begin{aligned}
& =0.057 \frac{\mathrm{kg}}{\mathrm{s}}(405 \mathrm{kj} / \mathrm{kg}-245 \mathrm{kj} / \mathrm{kg}) \\
& =0.057 \frac{\mathrm{kg}}{\mathrm{s}}\left(160 \frac{\mathrm{kj}}{\mathrm{kg}}\right)=9.12 \frac{\mathrm{kj}}{\mathrm{s}} \\
\text { i) } \quad \mathrm{COP} & =\frac{h 1-\mathrm{h} 4}{\mathrm{~h} 2-\mathrm{h1}}=\frac{405 \frac{\mathrm{kj}}{\mathrm{kg}}-245 \frac{\mathrm{kg}}{\mathrm{kj}}}{418 \frac{\mathrm{kj}}{\mathrm{kg}}-245 \frac{\mathrm{kj}}{\mathrm{kg}}}=\frac{160}{173}=0.92
\end{aligned}
$$


j) Tabel 4.7 Data Perhitungan Yang Akan Dipakai Buat Analisa

\begin{tabular}{|c|c|c|c|c|}
\hline Massa & $\dot{m}$ & Qc & Qe & COP \\
\hline 300 & 0.057 & 9,861 & 9.12 & \\
gram & $\frac{k g}{s}$ & $\frac{k j}{s}$ & $\frac{k j}{s}$ & 0.92 \\
\hline
\end{tabular}

\subsection{Perhitungan Unjuk Kerja Sistem Dengan Massa Refrigerant 400 Gram}

Tabel 4.8 Data analisa perhitungan massa Refrigeran R22 400 gram

\begin{tabular}{|c|c|c|c|c|c|c|}
\hline Masas & $\begin{array}{c}\text { P1 } \\
(\text { Bar })\end{array}$ & $\begin{array}{c}\text { T1 } \\
(\cdot \mathrm{C})\end{array}$ & $\begin{array}{c}\text { P2 } \\
(\mathrm{Bar})\end{array}$ & $\begin{array}{c}\text { T2 } \\
(\cdot \mathrm{C})\end{array}$ & $\begin{array}{c}\text { P3 } \\
(\mathrm{Bar})\end{array}$ & $\begin{array}{c}\text { T3 } \\
(\cdot \mathrm{C})\end{array}$ \\
\hline $\begin{array}{c}400 \\
\text { gram }\end{array}$ & 6,5 & 21,2 & 19,16 & 46,9 & 18.06 & 28.3 \\
\hline
\end{tabular}

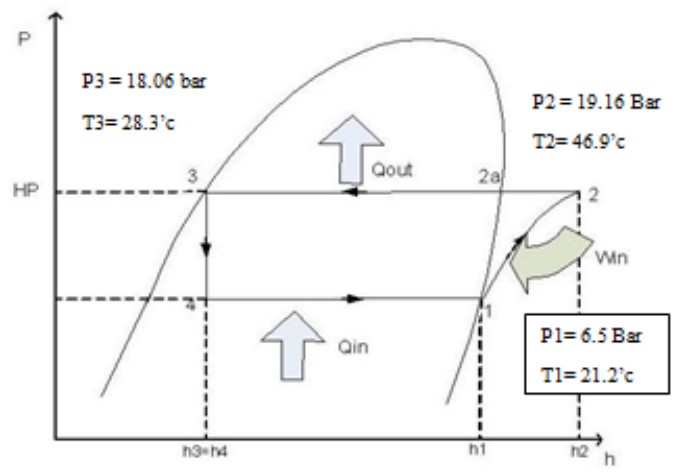

Gambar 4.5 Diagram P-h Siklus Kompresi Uap Aktual Dengan Massa Refrigerant 400 Gram.

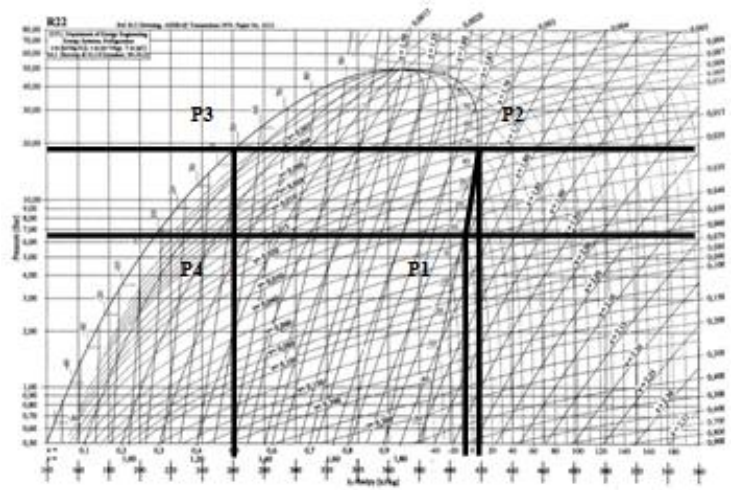

Gambar 4.6 P-h diagram variasi massa 400 gram

a) Keadaan titik 1

$\mathrm{P}_{1}=6,5$ bar

$\mathrm{T}_{1}=21,2^{\circ} \mathrm{C}$

$\mathrm{h}_{1}$ diketahui melalui $\mathrm{h}_{1}=410 \mathrm{kj} / \mathrm{kg}$

b) Keadaan titik 2

$\mathrm{P}_{2}=19,6$ bar

$\mathrm{T}_{2}=46,9^{\circ} \mathrm{C}$

Dari grafik pada lampiran maka diperoleh $\mathrm{h}_{2}=419 \mathrm{~kJ} / \mathrm{kg}$

c) Keadaan titik 3

$\mathrm{P}_{3}=18,06$ Bar

$\mathrm{T}_{3}=28,3^{\circ} \mathrm{C}$

Dari grafik pada lampiran maka diperoleh $\mathrm{h}_{3}=240 \mathrm{~kJ} / \mathrm{kg}$

d) Keadaan titik 4

Keadaan ini terjadi pada pipa kapiler yang tidak versible maka $\mathrm{h}_{4}=\mathrm{h}_{3}=240 \mathrm{~kJ} / \mathrm{kg}$

e) Efek refrijerasi :

$\mathrm{h}_{1}-\mathrm{h}_{4}=410 \mathrm{kj} / \mathrm{kg}-240 \mathrm{kj} / \mathrm{kg}=170 \mathrm{kj} / \mathrm{kg}$

f) Laju Aliran Massa Refrigerant : Kapasitas refrijerasi dibagi efek refrigerasi

$\mathrm{Wc}=\dot{m}\left(\mathrm{~h}_{2}-\mathrm{h}_{1}\right) \leftrightarrow$

$\dot{m}=\frac{W c}{h_{2}-h_{1}}=\frac{746 \text { watt }}{419 \frac{\mathrm{kj}}{\mathrm{kg}}-410 \frac{\mathrm{kj}}{\mathrm{kg}}}=\frac{0.746 \frac{\mathrm{kj}}{\mathrm{s}}}{419 \frac{\mathrm{kj}}{\mathrm{kg}}-410 \frac{\mathrm{kj}}{\mathrm{kg}}}$

$m=\frac{0.746 \frac{\mathrm{kj}}{\mathrm{s}}}{(419-410) \frac{\mathrm{kj}}{\mathrm{kg}}}=0.082 \frac{\mathrm{kg}}{\mathrm{s}}$

g) $\mathrm{Qc}=\dot{m}\left(\mathrm{~h}_{2}-\mathrm{h}_{3}\right)$

$$
\begin{aligned}
& =0.082 \frac{\mathrm{kg}}{\mathrm{s}}(419 \mathrm{kj} / \mathrm{kg}-240 \mathrm{kj} / \mathrm{kg}) \\
& =0.082 \frac{\mathrm{kg}}{\mathrm{s}}\left(179 \frac{\mathrm{kj}}{\mathrm{kg}}\right)=14,678 \frac{\mathrm{kj}}{\mathrm{s}}
\end{aligned}
$$

h) $\mathrm{Qe}=\dot{m}\left(\mathrm{~h}_{1}-\mathrm{h}_{4}\right)$

$$
\begin{aligned}
& =0.082 \frac{\mathrm{kg}}{\mathrm{s}}(410 \mathrm{kj} / \mathrm{kg}-240 \mathrm{kj} / \mathrm{kg}) \\
& =0.082 \frac{\mathrm{kg}}{\mathrm{s}}\left(170 \frac{\mathrm{kj}}{\mathrm{kg}}\right)=13.94 \frac{\mathrm{kj}}{\mathrm{s}}
\end{aligned}
$$

i) $\mathrm{COP}=\frac{\mathrm{h1}-\mathrm{h} 4}{\mathrm{~h} 2-\mathrm{h1}}=\frac{410 \frac{\mathrm{kj}}{\mathrm{kg}}-240 \frac{\mathrm{kg}}{\mathrm{kj}}}{419 \frac{\mathrm{kj}}{\mathrm{kg}}-240 \frac{\mathrm{kj}}{\mathrm{kg}}}=\frac{170}{179}=0.94$

j) Tabel 4.10 Data Perhitungan Yang Akan

\begin{tabular}{|c|c|c|c|c|c|c|}
\hline $\begin{array}{l}\text { Masas } \\
\text { (gram) }\end{array}$ & $\begin{array}{c}\dot{m} \\
(\mathrm{~kg} / \mathrm{s})\end{array}$ & $\begin{array}{c}Q c \\
(\mathrm{kj} / \mathrm{s})\end{array}$ & $\begin{array}{c}\mathrm{Q} \\
(\mathrm{kj} / \mathrm{s})\end{array}$ & COP & $T_{n=8}$ & $\mathrm{~T}_{\text {eut }}$ \\
\hline 200 & $0.034 \frac{\mathrm{kg} g}{\mathrm{~g}}$ & $6.086 \frac{\mathrm{kj}}{\mathrm{s}}$ & $5.338 \frac{\mathrm{kj}}{}$ & 0.877 & $26,3^{\circ} \mathrm{C}$ & $27.9^{\circ} \mathrm{C}$ \\
\hline 300 & $0.057 \frac{\mathrm{kg}}{\mathrm{g}}$ & $9.861 \stackrel{k j}{k}$ & $9.12 \underline{k j}$ & 0.92 & $20.1^{\circ} \mathrm{C}$ & $28.7^{\circ} \mathrm{C}$ \\
\hline 400 & $0.082 \frac{\mathrm{kg} g}{2}$ & $14.678 \frac{k j}{k j}$ & $13.94 \frac{k j}{k}$ & 0.94 & $18^{\circ} \mathrm{C}$ & $28.7^{\circ} \mathrm{C}$ \\
\hline
\end{tabular}
Dipakai Buat Analisa

\begin{tabular}{|c|c|c|c|c|}
\hline Massa & $\dot{m}$ & Qc & Qe & COP \\
\hline $\begin{array}{c}400 \\
\text { gram }\end{array}$ & $\begin{array}{c}0.082 \\
\frac{\mathrm{kg}}{\mathrm{s}}\end{array}$ & $\begin{array}{c}14,678 \\
\frac{\mathrm{kj}}{\mathrm{s}}\end{array}$ & $\begin{array}{c}13,94 \\
\frac{\mathrm{kj}}{\mathrm{s}}\end{array}$ & 0.94 \\
\hline
\end{tabular}

\subsection{Analisa Hasil Data Perhitungan}

\subsubsection{LAJU ALIRAN MASSA DENGAN VARIASI} MASSA

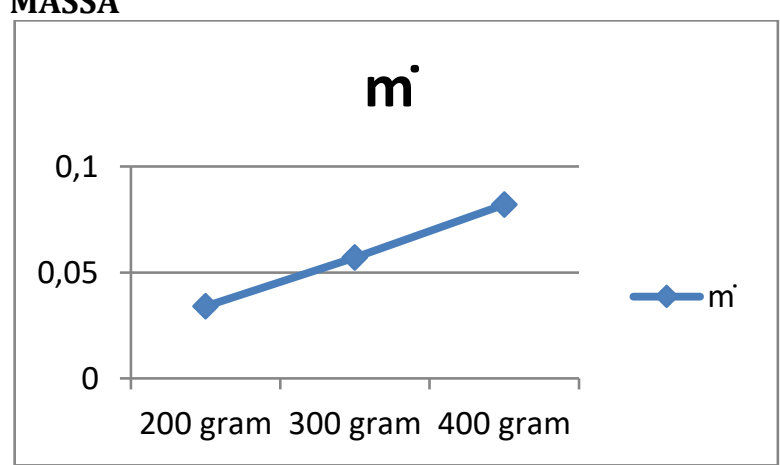

Gambar 4.4 Grafik hubungan laju aliran refrigerasi dengan variasi massa regrigerant

Dari grafik pada gambar 4.4 dapat dilihat bahwa laju aliran massa ketika massa refrigerant diisi 200 gram diperoleh $0.034 \frac{\mathrm{kg}}{\mathrm{s}}$ kemudian naik menjadi0.057 kg/s ketika massa refrigerant diisi 
300 gram. ketika massa refrigerant diisi 400 gram naik menjadi $0.082 \frac{\mathrm{kg}}{\mathrm{s}}$

\subsubsection{KAPASITAS PENDINGINAN PADA KONDENSOR (QOUT)}

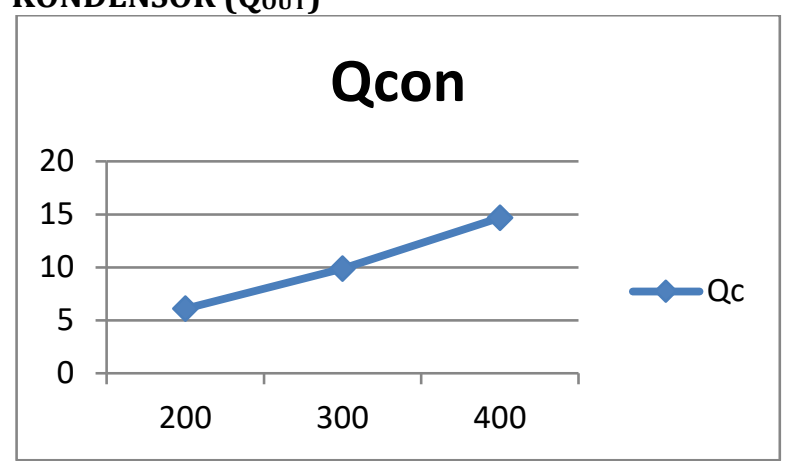

Gambar 4.5 Grafik hubungan antara antara kapasitas Pendinginan ( $\mathbf{Q}_{\text {con }}$ )Terhadap Variasi Massa Refrigerant

Dari grafik pada gambar 4.5 dapat diketahui bahwa nilai kapasitas pendinginan ketika massa refrigerant diisi 200 gram adalah $6.086 \frac{\mathrm{kj}}{\mathrm{s}}$ kemudian naik menjadi $9.861 \frac{\mathrm{kj}}{\mathrm{s}}$ ketika massa refrigerant diisi 300 gram. ketika massa refrigerant diisi 400 gram nilai kapasitas pendinginan (in) naik menjadi $14.678 \frac{\mathrm{kj}}{\mathrm{s}}$.

\subsubsection{Kapasitas Pendinginan pada Evaporator} (Qin)

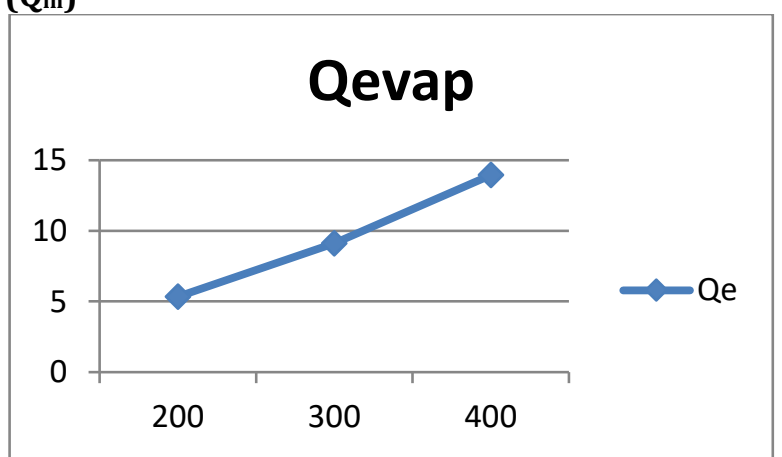

Gambar 4.6 Grafik Hubungan antara kapasitas Pendinginan ( $\mathbf{Q}_{\text {in }}$ )Terhadap Variasi Massa Refrigerant

Dari grafik pada gambar 4.6 dapat diketahui bahwa nilai kapasitas pendinginan ketika massa refrigerant diisi 200 gram adalah $5.338 \frac{\mathrm{kj}}{\mathrm{s}}$, kemudian naik menjadi $9.12 \frac{\mathrm{kj}}{\mathrm{s}}$ ketika massa refrigerant diisi 300 gram. Ketika massa refrigerant diisi 400 gram nilai kapasitas pendinginan ( in) naik lagi menjadi $13.94 \frac{\mathrm{kj}}{\mathrm{s}}$

\subsubsection{Koefisien Prestasi (COP)}

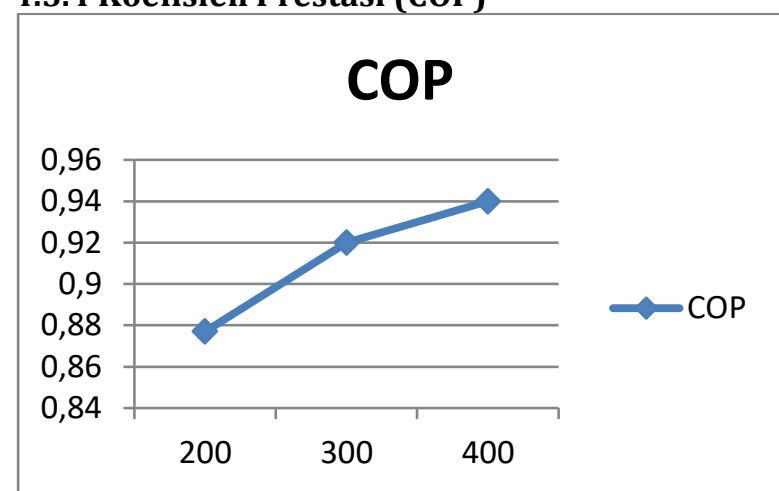

Gambar 4.7 Grafik Hubungan Antara Koefisien Prestasi (COP) Terhadap Variasi Massa Refrigeran

Dari grafik pada gambar 4.7 dapat diketahui nilai COP ketika massa refrigerant diisi 200 gram adalah 0.877 kemudian naik menjadi 0.92 ketika massa refrigerant diisi 300 gram. Ketika diisi 400 naik sedikit menjadi 0.94

\section{BAB V}

\section{KESIMPULAN}

A. Kesimpulan.

1. Dari hasil pengamatan diketahui kerusakan pada

a) Kompresor tidak bekerja maka Cek kelistrikan dan ganti kapasitor Running untuk 1 pk dengan ukuran $30 \mu \mathrm{F}$

b) AC tidak dingin maka Isi Freon (dicek lewat manifold, Freon dalam keadaan habis)

c) Dingin hanya sebentar maka dilakukan Tes kebocoran Freon, sambungan pada katup service bocor

d) Fan outdoor lemah maka dilakukan Ganti kapasitor fan sebesar $1.5 \mu \mathrm{F}$

e) Hembusan angin indoor lemah maka Bersihkan filter dalam unit indoor

2. Semakin besar laju aliran massa (m) , Kapasitas Pendinginan Kondensor ( Qc) , Kapasitas Pendinginan pada Evaporator (Qe) dan COP maka kinerja Ac tersebut semakin bagus dan tahan lama pemakaiannya

3. Koefisien prestasi yang paling bagus dari variasi massa refrigerant yang telah diteliti adalah massa 400 gram dengan COP 0.94

\section{B. Saran}

Berdasarkan kegiatan yang telah dilakukan, saran dari peneliti untuk pengembangan media pembelajaran untuk mahasiswa Universitas Maarif Hasyim Latief jurusan teknik Mesin antara lain :

1. Untuk bisa mengetahui gejala kerusakan pada AC split 
2. mengetahui cara dan kinerja AC dengan berbagai variasi massa dan pengaruh terhadap ac tersebut

\section{Daftar Pustaka}

Afifah, Y. N. (2016). ALIRAN TAK TUNAK FLUIDA NANO MAGNETOHIDRODINAMIK ( MHD ) YANG MELEWATI BOLA.

Afifah, Y. N. (2019). (2019). Analysis of Unsteady Magneto Hydro Dynamic ( MHD ) Nano Fluid Flow Past A Sliced Sphere Analysis of Unsteady Magneto Hydro Dynamic ( MHD ) Nano Fluid Flow Past A Sliced Sphere. IOP Conference Series: Materials Science and Engineering, $\quad 494, \quad 012033$. https://doi.org/10.1088/1757899X/494/1/012033

Afifah, Y. N., \& Putra, B. C. (2018). Model Matematika Aliran Tak Tunak Pada Nano Fluid Melewati Bola Teriris Dengan Pengaruh Medan Magnet. Teknika: Engineering and Sains Journal, 2(2), 119-124.

Catu, P., Evaporator, K., Ac, M., Merk, P. K., Pada, L. G., Variasi, T., ... Istimewa, D. (n.d.). UNIVERSITAS YOGYAKARTA. 1-7.

Demak, R. K., Basri, M. H., Mesin, J. T., \& Teknik, F. (2017). PENGARUH VARIASI MASSA REFRIGERAN TERHADAP KINERJA AIR CONDITIONER WATER HEATER ( $A C W H$ ) EFFECT OF REFRIGERANT CHARGE ON THE PERFORMANCE OF AN AIR CONDITIONER WATER HEATER ( ACWH).

Pendinginan, P. B., Dan, P., Air, P., Di, C., Autocad, R., \& Akhir, T. (2012). Universitas diponegoro.

Pramithasari, E. R., Teknik, J., Dan, R., Udara, T., \& Bandung, P. N. (n.d.). ANALISIS PERFORMANSI AC SPLIT INVERTER 1PK LG.

Purwanto, E., Ridhuan, K., Studi, P., Mesin, T., Teknik, F., \& Muhammadiyan, U. (n.d.). PENGARUH JENIS REFRIGERANT DAN BEBAN PENDINGINAN TERHADAP KEMAMPUAN KERJA MESIN PENDINGIN. 3(116), 11-16.

Santosa, B. (2017). Analisa pemakaian energi listrik dan cop pada AC split 900 watt menggunakan refrigeran hidrokarbon $M C-22$ dan $R-22$. 12(1), 25-28.

Yunita Nur Afifah, MNH Qomarudin, \& Imamatul Ummah. (2020). Optimal Control Model Pemanenan Prey-Predator di Area Konservasi Ikan. Buana Matematika: Jurnal Ilmiah Matematika Dan Pendidikan Matematika, 10(1), 1-16. https://doi.org/10.36456/buanamatematika. v10i1.2410

Gunawan, E. et al. (2019) 'Analysis of the Effect of Current Flow Variations in GTAW on SS 400 Plate Material Connected with SUS 304
Stainless Steel Plate Against Tensile Strength and Hardness with ER308L Electrodes', Journal of Physics: Conference Series, 1175(1). doi: 10.1088/1742-6596/1175/1/012277. 